\title{
Information Systems: The Prospects of Bi-directional Counter System in the Hotel Industry
}

\author{
Edje E. Abel \\ Department of Mathematics and Computer Science, \\ Delta State University, Abraka P.M.B 01, Delta \\ State Nigeira
}

\author{
Ureigho Roy Joel \\ Department of Mathematical, Computer and \\ Physical Science, Federal University of Otuoke, \\ Otuoke P.M.B 126, Yenagoa, Bayelsa State, \\ Nigeria
}

\begin{abstract}
This paper discusses the application of information systems and throws more light on the prospects of bi-directional counter system in the hotel industries. Terrorists group around the globe often attack social areas and public buildings such as the hotel. The after mouth of any terrorist attack always results to human deaths and injuries, which cannot be accounted for by most hotel managements. In most cases, the total number of human casualties is often estimated by trial and error, it is even difficult to identify these casualties. No proper system is being put in place to checkmate this issue, as some of these hotels rely heavily on CCTV camera(s) which is not always effective. Bidirectional counter system is proposed that would complement CCTV cameras in resolving this prevalent problem. Bi-directional counter system is a device that keeps records of number of times an event occurred. Therefore, bi-directional counter system model was formulated and compare it to other existing ones and end with a conclusion.
\end{abstract}

\section{Keywords}

Centralised Reservation System (CSR), Point-Of-Sale (POS), Digital Electronic Counter System (DECS), Enterprise Resource Planning (ERP) and Bi-directional counter system (BCS)

\section{INTRODUCTION}

The rate at which the hotel managements are embracing new trends in Information systems has made the industry to be more competitive than ever. Presently, most hotel management in the developed and developing countries are investing enormously in information systems, in other to enhance the effectiveness and efficiency of rendering services to prospective guests. Also, provide management with timely information for the purpose of business monitoring and decisive business decision making. Indeed, most successful hotel management entrepreneurs agreed to the fact, that the use of Information systems for business processes have kept them to be more competitive in the hospitality industry.

[8], currently view Information Systems as Operation Support Systems (OSS) and Management Support Systems (MSS). Operation support systems deal on business transaction processes, which involves communication among hotel staff members and prospective guests. That of management support systems enables hotel top managements to checkmate business operations within and outside the hotel premises, as well as effective business decision making.

According to [5], must hotels in the world use Information Systems as to ease their tasks such as taking reservation, room management, telecommunication and guest accounting. The use of Information System (IS) in hotels has tremendously assists managements to cut down cost, enhance productivity and profitability. The major roles of Information Systems in the hotel industry are "to achieve competitive advantage, developing new products, attain customer intimacy and services as well as ensuring survival" [19].

\section{APPLICATION OF INFORMATION SYSTEMS IN THE HOTEL INDUSTRY}

Information Systems deal with planning, management, and use of Information Technology tools to help hotel managements perform all the tasks related to information processing and management [26]. Information tools includes computer based hardware and software, as well as the internet and telecommunications systems deployed in the hotel industry, to facilitate business operations thereby providing timely information for decision making.

[19], defined Information System (IS) as a set of interrelated components that collect (or retrieve), process, store, and distribute information to support decision making and control in an organization. Information systems also offer managers with intelligent information on the organization's present recital. This is used to examine and manage business operations as well as foretell future performance.

An information System is a system in which human participants and machines perform work (processes and activities) using information, technology, and other resources to produce informational products and services for internal and external customers [30]. Instances of information systems include processes committed to create business plans, implement computer programs, producing financial statements, establishing prices for hotel accommodation and other related services such as prices for beverages and food menus e $t \mathrm{c}$.

The hotel industry has three primary services which they provide to prospective guest and customers. These include accommodation and Restaurant/Bar, letting out of Halls for social (Conferences, Marriage ceremonies and birthday parties e t c) activities. Information Systems has really played a major role in these areas of services rendered by the hotel industry. For instance, Centralized Reservation System (CSR) via the internet enables prospective guests to determine the category of accommodation service rendered by any hotel establishment. They easily make their choice of rooms and pay instantly at their own convenient. With this system(Central Reservation System) in place, it will "provide individual hotels and managers in the chain with a tool to increase reservations, maximize sales, implement yield 
management, enhance market capability and improve quest services" [3].

Hotel receptionist uses computer systems to monitor reservation bookings, check-in and check-out clients, provide timely information about the total expenditure for a particular guest and make bills and invoices available. This information is distributed internally across to other department in the hotel such as the accounting and top management via a local area network system; thus, for monitoring the revenue and the growth of the hotel. Point-Of-Sale (POS) systems are widely used in the hotel industries specifically at the restaurant/bar section. According to [25], point-of-sale system (POS) is either a stand-alone machine or network of input and output devices used by restaurant employees to accomplish their daily activities. For instance, taking food and drinks order from guests, sending food menu already ordered by guest to the kitchen electronically, recording of total sale made on a daily basis, preparing bills and receiving payments from guest's e t c.

Customer relationship management system has also been employed in the hotel industry. Its main purpose is to assist hotel managers on how best to provide quality services to her guests in other to retain their patronage. [7] state that CRM is focused on business strategies that aim to increase satisfaction and customer loyalty by offering customers more options and customized services for everyone. In other words, giving prospective guest the free will to make option on how the hotel management can offer better services that will maximize their satisfaction. With the ever increasing competition for market dominance, most hotel managements have utilize CRM systems to improve their business intelligence, decision making, customer relations, quality of service and product offerings [34].

Enterprise Resource Planning (ERP) Systems has gained significant recognition in the hotel industry mostly in the developed countries. ERP tends to create a platform that interconnects the entire departments in a hotel together for the purpose of providing managers with a global vision and realtime all operations, solving the problems of disintegration and fragmentation [24]. In other words, it provides a platform of making the operations of each department in the hotel to be visible to all. For instance, the accounting department have a direct access to information or operations of the Sales department at any given time e $\mathrm{t} c$.

\section{DIGITAL ELECTRONIC COUNTER SYSTEM}

A Digital Electronic Counter System (DECS) is used for counting the number of pulses coming at the input line in a specified time period [9]. It is made up of a memory that enables it to retain information. An electronic counter system can be synchronous or asynchronous. Asynchronous counter system is one in which the flip-flop within the counter do not change states at exactly the same time because they do not have a common clock pulse [35]. It means that the occurrence of events in asynchronous counter does not have a permanent time connection with each other and do not take place at the equal time.

Synchronous counter system has a timepiece signal that manage all flip-flop status. In view of the fact that a timepiece "controls all flip-flops simultaneously, there are no cumulative delays that result when a clock signal ripple through the stages" [5]. This means that synchronous counters has a specific time associated with each other and takes place at similar time. Also, synchronous counter system can be implemented to count in up-down modes. A good example of synchronous counter system is the bi-directional counter system.

\section{BI-DIRECTIONAL COUNTER SYSTEM}

Bi-directional counter system (BCS) is a counter that can change its state in either direction, under control of an updown selector input [18]. It is made up of a circuit device which determines the numbers of count that can be done in up-down modes depending on the position of the selector. Selector responds to input information, which consists of either to add or subtract a number controlled by the up-down mode. In other words, up-down modes enable the device to accept a number in incremental patterns and remove numbers by decrementing patterns from existing gates. Bi-directional counter system is often "used to count the number of persons entering a hall in the up mode and leaving the hall in the down mode by decrementing existing gate" [2].

According to [2], bi-directional counter system is a visitor counting for measurement of the visitor traffic entering and exiting offices, malls, sports venues in other to maximize the efficiency and effectiveness of employees and the potential sales of an organization. This means that it can be used by managements of an organization to monitor the hours of work done per employee on a daily routine, as to facilitate the computation of wages earned either on a weekly or monthly basis. Also, can be use to determine the type of products that are not highly demanded by customers in order to cut down production cost on such products.

Bi-directional counter system is mainly made up of a micro controller, transmitter and receiver. The micro controller is referred to the central processing unit where all computational counting processing are done. Transmitter which is often implemented by sensor transmits signals from the receiver to the micro controller. Micro controller then manipulates the received signals and displays the outcome on an output device (e.g. LCD or Monitor). The microcontroller carries out its operations with a clock timer, transceiver detection circuit and a logic control that is implemented around transistors, amplifiers and flip-flop.

Microcontroller consists of five major components which include the processor, memory, Interrupt Controller, timer/Counter and the input/output component. The processor of the controller is similar to that of the computer system as it contains the control unit, registers and arithmetic logic unit. That of the memory is divided into two sections known as data and program memory. The data memory usually controls how data are transmitted from one component to another. Interrupts Controllers are useful for interrupting the normal program flow in case of (im-portant) external or internal events [14]. The Timer/Counter is used by the controller to determine the time at which events occurs or enumerate events.

\section{RESEARCH METHODOLOGY}

Research Methodology is the "procedures by which researchers go about their work of describing, explaining and predicting phenomena [27]. The main purpose of research methodology is to assist researchers with the frame work plan so that they can actualize their research aim. The researchers 
have decided to use the following listed procedures in other to actualize the research goal.

- Problem Statement

- Analysis of Proposed System

- Systems Comparisons

Problem statement throws more light on the challenges and problems that may be resolved or drastically reduces to the barest minimum; with the application of new or the enhancement of an existing system model. Real life problems or challenges are often resolving scientifically, either via natural or physical scientific methods. Proposed System Solution is about the analyzing the system proposed to be used for resolving specific challenges or problems. Design or implementation of the system model is described based on how it may resolve the challenges within the confine of the research area.

System Comparisons is basically comparing the proposed system solution model with an existing model. Describing their relationships and what make the proposed system solution more advantageous than that of the existing system models.

\section{PROBLEM STATEMENT}

Presently, Terrorist organizations across the globe are targeting any social gathering to perpetuate their nefarious activities. The hotel industry is not left out from this gruesome threat, especially conference halls and restaurants situated in hotels. Potential terrorist attacks in hotel premises are deemed fatal as many death casualties will be expected especially in reputable hotels. Take for instance the terrorist attack on Taj hotel in Mumbai, India in the year 2008. It was reckoned that "101 death casualties were recorded and more than 297 people were injured" [6]. What about the present terrorist attack on Tunisian Hotel was 28 death casualties were recorded [4]. Despite the huge amount of death casualty's hotel management find it difficult to identify and account for the details about the actual number of death casualties occurred in such gruesome attacks on their guests.

Some of the diseased and displaced guest may prove abortive to identify due to lack of security information about the where about before or after the unexpected incidence occurred. However, CCTV systems have help very little to determine the level of injuries and death casualties caused by unexpected incidence (e g. suicide bombing or terrorist attack) that may occur in the hotel premises. CCTV systems tend to be very stressful and inefficient in analyzing when different individuals come into and leave the hotel premises. Due to the fact that not all premises of the hotel will be captured by the CCTV systems. Also, it cannot account for the total number of persons or potential guest that may have enter into or leave the hotel premises.

\section{PROPOSED SYSTEM SOLUTION}

A proposed system solution called Bi-directional Counter System (BCS) was modeled. That will enable hotel management to account for the actual number of death casualties and those who may have sustained injuries, as well as providing timely information to the diseased relatives and higher authorities. The system consists of a digital camera, transceivers, micro-controller (processor), actuators and database unit.

The transceivers accept inputs signals (Infra-red) whenever a guest about to gain entry through the entrance door or exits the hotel complex through the exit doors. At the capturing of the input signal by transceivers, the actuators are alerted and therefore trigger the camera to snap the guests a short. The image of the guest and other personal information about its arrival or exiting the hotel premises are transmitted to the micro-controller. The micro-controller assigned a unique number to the image picture received, and performs computation of guests that are present or have left the hotel complex.

The micro-controller is also responsible for determining the time at which a guest arrive or left the hotel premises. It has a mechanism called the flip-flop which increases its count as prospective guest passes through the hotel entry door and decreases the count as they left the hotel complex by passing through the exit door. However, the information (such as their photograph, the time at which they enter and exit the hotel) about those who have left the hotel premises is automatically transferred from the micro-controller to the hotel management database. Information about the guests that are still in the hotel premises can also be accessed on the management database system as well as on the micro-controller via monitors. The database system is serving as a backup system which can only be accessed by the hotel management. See model structure below for more insight. 


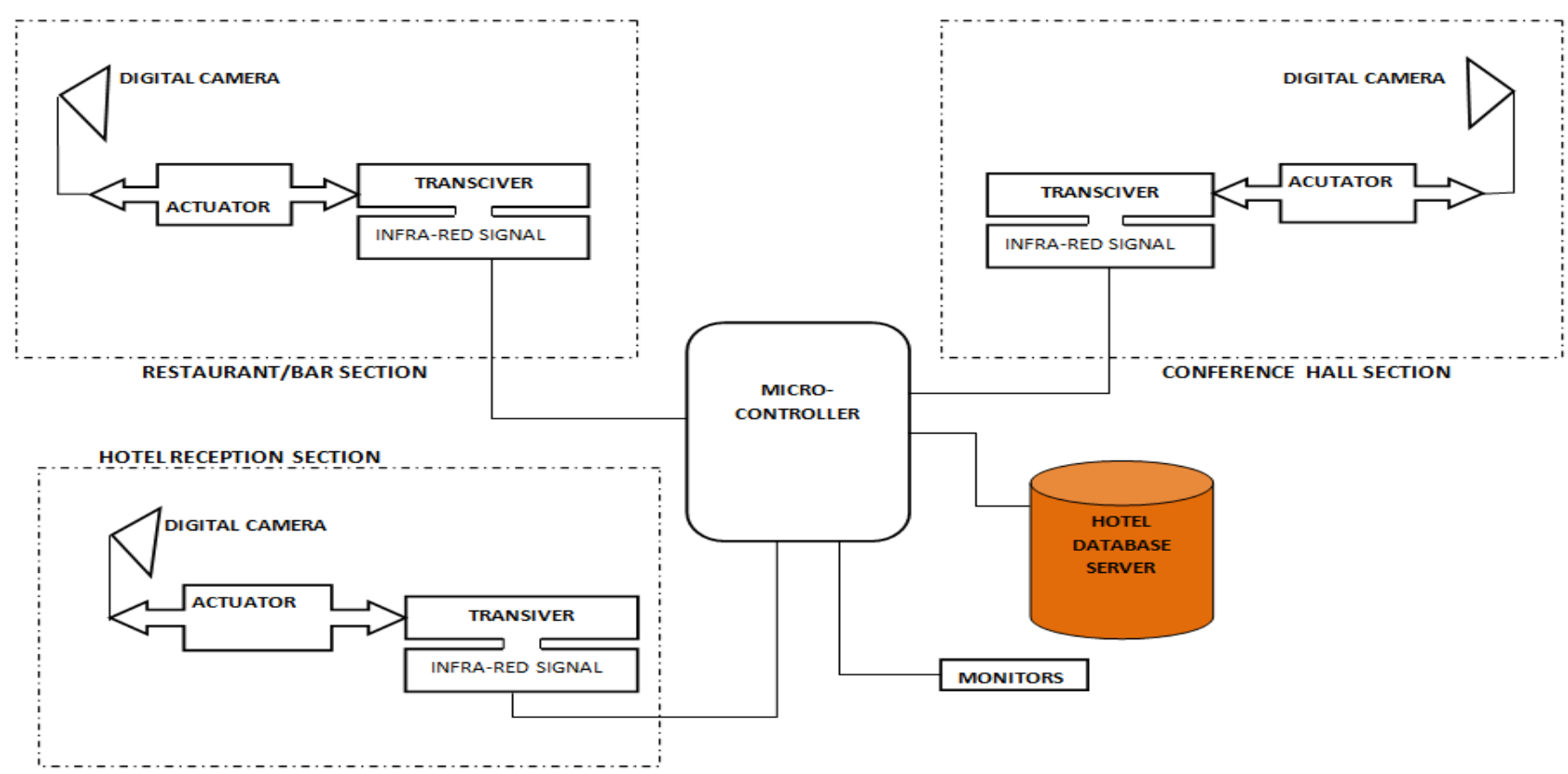

Fig 1.1: Proposed System Model Structure

The model structure above shows there are three transceivers, actuators and digital cameras which are positioned at strategic locations (Restaurant/Bar, Conference and Reception sections) within the hotel premises. These devices are then connected to the micro-controller (Processor). Monitor(s) is connected to the micro-controller as well as the hotel database server. When an individual is captured at a specific section (e g. Restaurant/Bar) of the hotel, and he/she then walked to another location (e g. Conference hall). Its detail would still be retained in the micro-controller and the number counts is unaltered. The only changes that would be observed are the time at which he/she left the restaurant.bar and the time it get to the conference hall. However, if the guest decides to exit the hotel by passing through the reception exit door, its details would be transferred to the hotel management database server which will then prompt it to be deleted from the microcontroller.

The transceivers are embedded in the floor close to the entry and exit doors of the locations (Restaurant/Bar, Conference hall and Reception). The digital cameras are mounted at the top edge of these doors. Infra-red signal is used to capture or sense the presence of an individual. It was used because it can sense two or more signals at the same time or simultaneously.

The micro-controller is made up an in-built clock and circuit control logic. The circuit control logic uses the flip-flop mechanism to count and displays the number of guests presents within the hotel complex. The processing speed of the micro-controller is estimated to be about 5.6 Gigahertz with the memory of 3.0 Gigabyte. As the system is dealing with numerous photographic images of guests and other individual presents within the hotel complex $24 / 7$ basis.

\section{COMPARISON OF SYSTEMS}

In this section, comparison is done between the proposed bidirectional system model and other existing ones in use. Similar framework approach is considered because "it enhances the external strength by setting up the area which the proposed system can be generalize [15]. Other existing bidirectional systems mainly comprises of a transceivers, microcontroller. The transceivers are only receives and transmit sensor signals to the microcontroller. This type of bidirectional counter are mostly used to turn on/off security alarm automatically especially in industrial buildings. See diagram below for insight.

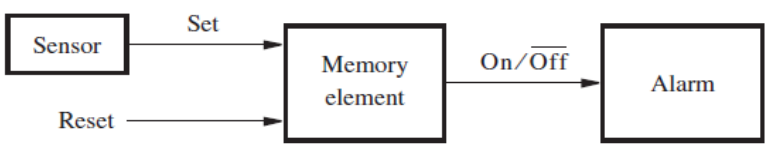

Fig 1.2: Existing Bi-directional Counter System [21]

Another existing bidirectional counter system is called the Digital Visitor Counter. According to [22], digital visitor counter system is mainly used to measure and display the number of persons entering in any room like seminar hall and conference room. Furthermore, it comprise of a transmitter, receiver, micro-controller and LCD display unit. See diagram below for illustration.

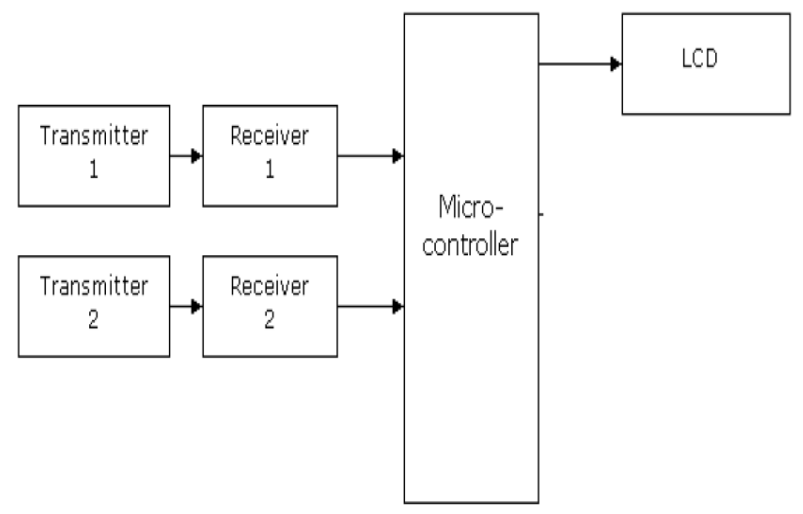

Fig1.3: A Digital Visitor Counter [22]

The existing digital visitor counter system model, shows that it comprise of two transmitter and receivers connecting to the micro-controller which then linked to an LCD. This type of bidirectional counter system is "used in various rooms like seminar hall, where the capacity of room is limited and should 
not be exceeded whereby the LCD unit would display the actual number of persons inside the room" [22].

Both existing systems are using sensor signal which is not always the best because it cannot detect or sense more than one object or individual at the same time. That is why the researchers chose to use infra-red in the proposed system, due to its ability to detect two or more persons at the same.

The existing systems only have a micro-controller and memory device which may crash down due to overloading of data. On like the proposed system that has a backup database server. The backup database server provides tremendous support by storing up data for the micro-controller. This gives the micro-controller the leverage to process data effectively and efficiently by maximizing its memory and hard disk capacity.

The proposed system that captures the image of every individual, counts and stores the total number of persons presents in hotel at any given time, indicating the time at which they came inside the hotel and the time they left the hotel complex. On like the existing systems are mostly used to turn on/off alarms as well as determining the number of persons a room or hall can accommodate.

\section{CONCLUSION}

The proposed system possesses diverse potentials as it could be used in other industrial complex and public building such as shopping centre and cinemas e t $\mathrm{c}$. When this intended system is fully implemented, it will go a long way to support hotel managements with vital and timely information about the number of human casualties (death/injured) within the hotel building from unexpected terrorist attacks (suicide bomber, shooting aimlessly e $t \mathrm{c}$.). CCTV cameras are not to be discarded but to be use along side with the propose system. The researchers intend to develop an embedded system called a digital bi-directional counter system in the future.

\section{REFERENCES}

[1] A.Sahu (2011). "Counter and Registers", http://www.iitg.ernet.in/asahu/cs221/Lects/Lec20.pdf, [Access Date: 10-08-2015].

[2] Akshay Mathur and Singh Nagla (2007). "Microcontroller-based bidirectional Visitor counter", http://www.hbeonlabs.com/EFY\%20Projects/BiDirection al\%20Visitor\%20Counter.pdf [06-08-02015]

[3] Albert Kwansah Ansah and Victoria S. Blankson (2012). "The use of Information and Technologies (ICT) in Front Office Operations of Chain Hotels in Ghana", International Journal of Advanced Computer Science and Applications, Volume No. 3, Issue No. 3, https://thesai.org/Downloads/Volume3No3/Paper13The_Use_of_Information_and_Communication_Technol ogies\%28ICT\%29in_Front_Office_Operations_of_Chain _Hotels_in_Ghana.pdf [Accessed Date: 06-08-2015].

[4] Anthony Bond (2015). "Tunisia hotel attack: Shocking pictures show bodies lying on beach as eyewitnesses tell of terror" Mirror Newspaper, Published: 26 June 2015, http://www.mirror.co.uk/news/world-news/tunisia-hotelattack-shocking-pictures-5953282, [Accessed Date: 1008-2015].

[5] Azdel Abdul Aziz, Mohd Faeez Saiful Bakhtiar, Mohd Syaquif Yasin Kamaruddin and Noor Azmi Ahmad (2012). "INFORMATION AND COMMUNICATION
TECHNOLOGY APPLICATION'S USAGE IN HOTEL INDUSTRY", Journal of Tourism, Hospitality \& Culinary Arts, VolumeNo.4,Issue 2, Page 34-38, http://www.jthca.org/Download/pdf/V4\%20IS2/chap\%2 04.pdf [Access Date: 03-08-2015].

[6] BBC (2008). "Mumbai rocked by deadly attacks", http://news.bbc.co.uk/2/hi/south_asia/7751160.stm, Published: $28^{\text {th }}$ of November 2008, [Accessed Date: 0908-2015].

[7] Boris Milovic (2012). "Social Media and eCRM as a prerequisite for Hotel Success", Journal of Information Systems, Volume No. 7, Issue No. 3, Page 026-031, http://www.ef.uns.ac.rs/mis/archive-pdf/2012\%20\%20No3/MIS2012-3-4.pdf [Accessed Date: 06-08-2015]

[8] D. V. Tesone (2006). "Hospitality Information Systems and E-commerce", second Edition, John Wiley and Sons, Inc. 222 Rosewood Drive, Danvers, U.S.A.

[9] DAE (2010). "Counters" http://www.daenotes.com/electronics/digitalelectronics/counters-types-of-counters, [Accessed Date: 11-08-2015].

[10] Daniela Garbin PraniČević1, Nikša Alfirević,, and Mojca Indihar Štemb erger (2011). "INFORMATION SYSTEM MATURITYAND THE HOSPITALITY ENTERPRISE PERFORMANCE", ECONOMIC AND BUSINESS REVIEW, VOL No. 13, Issue No. 4,Page 227-249

[11] Dean A. Koutroumanis (2011). "Technology's Effect on Hotels and Restaurants: Building a Strategic Competitive Advantage", Journal of Applied Business and Economics, Volume No.12, Issue No.01, http://www.pua.edu.eg/PUASite/uploads/file/Tourism/Fa 11\%202013/THM\%20201/ch\%2013.pdf [06-08-2015].

[12] Ehab Abdul-Razzaq Al-Hialy (2009). "Synchronous Counters", http://www.uobabylon.edu.iq/eprints/paper_1_782_163.p df, [Accessed Date: 13-08-2015].

[13] Eric Yu (2004). “ Information Systems (in the Internet Age)” http://www.cs.toronto.edu/pub/eric/PHIC04.pdf [Accessed Date: 07-08-2015]

[14] Gunther Gridling and Bettina Weiss (2007). "Introduction to Microcontrollers", https://ti.tuwien.ac.at/ecs/teaching/courses/mclu/theorymaterial/Microcontroller.pdf, [Accessed Date: 28-082015].

[15] Hansen H. B. and Kautz K., (2005). Grounded Theory Applied-Studying information Systems Development Methodologies in Practice, Proceedings of the $38^{\text {th }}$ International Conference on System Sciences, Hawaii, page $1-10$

[16] HBeonLabs (2011). "Introduction: Automatic bidirectional visitor counter for controlling room light using 8051 Microcontrller (AT89S52)", http://www.hbeonlabs.com/reports/IR\%20birectional\%2 0Visitor\%20counter.pdf [Accessed Date: 06-08-2015]

[17] HD Clifton, DC Ince and AG Sutcliffe (2000). "Business Information Systems", Sixth Edition, Pearson Education 
Limited, Pearson, Upper Saddle River, New Jessey, U.S.A.

[18] Himanshu Choudhary (2012). "Automatic bidirectional visitor counter using 8051 microcontroller (AT89C51)", http://www.engineersgarage.com/microcontroller/8051pr ojects/Bidirectional-visitor-counter-AT89C51-circuit, [Accessed Date: 12-08-2015].

[19] Kenneth C. Laudon and Jane P. Laudon (2009). "Essentials of Management Information Systems", Eight Edition, Pearson Education Inc, Upper Saddle River, New Jessey, U.S.A.

[20] Maxwell (2001). "Shift Register", https://maxwell.ict.griffith.edu.au/yg/teaching/dns/dns_m odule3_p3.pdf, [ Accessed Date: 10-08-2015].

[21] Mheducation (2002). "Flip-Flops, Registers, Counters, and a Simple Processor", http://www.highered.mheducation.com/sites/dl/free/.../56 549/vra23151_ch07.pdf, [Accessed Date: 09-08-2015]

[22] Micronics Technologies (2015). “ Digital Visitor Counter", http://www.projectsof8051.com/, [Accesssed Date: 27-08-2015].

[23] Muhammad Ali Mazidi and Janice Gillispie Mazidi (2008). "Micorcontroller and Embedded" Systems", http://jsjyl.chd.edu.cn/The_8051_Microcontroller_and_E mbedded_Systems_Using_Assembly_and_C.pdf, [Accessed Date: 11-08-2015].

[24] Paula Serdeira Azevedo, Carlos Azevedo and Mario Romao (2014). "Application Integration: Enterprise Resource Planning (ERP) systems in the hospitality industry-A case study in Portugal", Conference on Enterprise Information Systems / ProjMAN and International Conference on Health and Social Care Information Systems and Technologies, Issue No. 16, Page 52-58, http://ac.elscdn.com/S2212017314002941/1-s2.0-

S2212017314002941-main.pdf?_tid=a57cadc6-3c23-

$11 \mathrm{e} 5-9 \mathrm{~d} 52-$

00000aab0f26\&acdnat=1438856130_84b4a4e02df92955 584a0f75cd2d548b, [Accessed Date:06-08-2015]

[25] Peter D. Nyheim, Francis M. McFadden and Daniel J. Connoly (2005). "Technology Strategies for the Hospitality Industry", First Edition, Pearson Education Inc, Upper Saddle River, New Jessey, U.S.A.

[26] R. Kelly Rainer Jr. and Casey G. Cegielski (2011). "Introduction to Information Systems supporting and transforming Business", Third Edition, John Wiley and Sons, Inc, 222 Rosewood Drive, Danvers, U.S.A.

[27] S. Rajasekar, P. Philominathan and V. Chinnathmbi (2013). "Resaerch Methodology", http://arxiv.org/pdf/physics/0601009.pdf, [Accessed Date: 18-08-2015].

[28] Satish Chander (2010). "Project Report on Bidirectional Visitor Counter", https://www.academia.edu/4874472/PROJECT_REPOR T_ON_BIDIRECTIONAL_VISITOR_COUNTER_For_ the_partial_fulfillment_of_the_degree_of_associated_Me mbership_awarded_by_SATISH_CHANDER, [Accessed Date: 12-08-2015]

[29] Srinivas Nowduri (2000). "Management information systems and business decision making: review, analysis, and recommendations", Journal of Management and Marketing Research, http://www.aabri.com/manuscripts/10736.pdf [Accessed Date: 07-08-2015].

[30] Steven Alter (2008). "Defining Information Systems as Work Systems: Implications for the IS field", Business Analytic and Information Systems, http://repository.usfca.edu/cgi/viewcontent.cgi?article=1 021\&context=at [Accessed Date: 08-08-2015]

[31] TechnologyinHospitality Industry: A CaseStudy from Mures County", http://www.scientificpapers.org/wpcontent/files/1421_Oltean_Flavia-

An_Empirical_Research_Regarding_Information_Techn ology_in_Hospitality_Industry.pdf [Accessed Date: 0608-2015]

[32] Uotechnology (2000). "Digital Electronics", http://www.uotechnology.edu.iq/depeee/lectures/3rd/electrical\%20\&\%20communication $\% 20$ shared/Electronics\%202/2.pdf, [Accessed Date: 10-082015].

[33] Vickie R. Westmark (2004). "Definition for Information System Survivability", Proceedings of the $37^{\text {th }}$ Hawaii International Conference on System Sciences, http://citeseerx.ist.psu.edu/viewdoc/download?doi=10.1. 1.106.5586\&rep=rep1\&type=pdf [Accessed Date: 07-082015]

[34] Yi Wen Fan and Edward C. S. Ku (2007). "The Impact of Customer Service through Information Systems for Lodging Industry", http://www.jgbm.org/page/6\%20Edward\%20C.S.\%20Ku \%20.pdf [Accessed Date: 06-08-2015].

[35] Yongsheng Gao (2006). "Asynchronous Counters, Synchronous Counters, Design of Synchronous Counters, Shift Registers, Johnson \& ring counters, Applications etc" http://educypedia.karadimov.info/library/dns_module3_p 1.pdf, [Accessed Date:12-08-2015] 